\title{
Scandal, Protection, and Recovery in the Cabinet
}

\section{Torun Dewan}

Department of Government, London School of Economics, London WC2 2AE, United Kingdom

$$
\text { t.dewan@lse.ac.uk }
$$

\author{
David P. Myatt \\ Department of Economics, University of Oxford, Oxford, OX1 3UQ, United Kingdom \\ david.myatteeconomics.ox.ac.uk
}

\section{Originally June 2005. Final revision for the American Political Science Review, May 2006.}

\begin{abstract}
Empirical evidence suggests that a prime minister benefits from firing ministers who are involved in political scandals. We explore a model in which scandals are positively related to policy activism, so that a prime minister may wish to protect a minister from resignation calls. We find that protection can sometimes discourage activism: it enhances the value of a minister's career and hence encourages him to "sit tight" by moderating his activities. On the other hand, an exogenous increase in exposure to scandals may lead a minister to "live for today" by pursuing controversial policies. The prime minister's ability to protect ministers is limited by her short-term incentive to fire. She may, however, enhance her credibility by building a collective reputation with the cabinet; the heterogeneity of cabinet membership plays an important role.
\end{abstract}

Acknowledgements. For helpful comments and suggestions we thank Keith Dowding, Valentino Larcinese, Christian List, Ken Shepsle, seminar participants at ECPR Granada, Harvard University, the London School of Economics, the Midwest Political Science Association, and the University of Montreal, Lee Sigelman and three anonymous referees. 
In liberal democracies the scrutiny of a minister, via legislative bodies and media attention, often leads to calls for his resignation. These calls are sometimes heeded, and a minister resigns. In other circumstances, the support of the prime minister protects the minister. Recent research reveals the incentives that are at work (Dewan and Dowding, 2005; Huber and Martinez-Gallardo, 2004; Indridason and Kam, 2005b). In particular, Dewan and Dowding (2005) have shown that a government's popularity rises when a call for a resignation is heeded. Thus a prime minister can adjust for the negative effect of scandals and policy failures by replacing the relevant minister.

While firing a minister generates a positive public reaction, should the prime minister always take this course of action then there may be repercussions. In particular, a minister then has an incentive to reduce his exposure to resignation calls. This may be a good thing if it leads away from activities that the prime minister dislikes; if, for example, ministers refrain from dipping into the public purse, then all is well and good. On the other hand, it may detract from the executive's objectives: resignation calls may stem from policy failures following desirable policy initiatives, and so the prime minister may wish to protect a policy-active minister.

We might think that the prime minister can differentiate between policy failures and personal scandals. Things may not be so clear cut, however, since active ministers may attract attacks from the enemies of policy initiatives. A negative campaign need not focus on the policy-relevant aspects of the minister's job; things can and do get nasty. To illustrate this, consider the 1992 resignation of David Mellor, the British Secretary of State for Heritage whose brief included press regulation. Mellor had voiced concerns about press intrusion into privacy and was sceptical about the role of the Press Complaints Commission, a self-regulating non-statutory body. He remarked that the "the popular press is drinking in the last-chance saloon." Mellor had a reputation for taking on the media having pushed the 1990 Broadcasting Act through Parliament and ending what many Conservatives thought was a lack of accountability of private TV companies. Mellor resigned after tabloid allegations that he had accepted air tickets and the use of a villa from 
Monica Bauwens, the daughter of a leading official in the Palestine Liberation Organization. The tabloids also highlighted his affair with actress Antonia de Sanchez. There is little doubt that The People newspaper saw this as a warning shot about press freedom. Doig (1993) described it as "an attempt to underline the consequences of tighter restrictions on what the press could publish." Thus it may be costly to develop policy initiatives if these lead to resignation pressures following a scandal, where "scandal" is a generic term for either a policy failure or personal impropriety.

In our formal model, policy activism brings higher performance but also increases the risk of a political scandal. A minister minimizes this risk by sitting tight, maintaining the status quo in order not to tread on the toes of the parties, lobbies, and media who are opposed to reform. ${ }^{1} \mathrm{We}$ assume that the prime minister and cabinet members share the same political objectives. Nevertheless, there is a classic moral-hazard problem: a minister faces the sack following a scandal and would like to keep his job, whereas the prime minister would be happy to replace him. This aspect of the relationship between the prime minister and her cabinet members is an important link in the "chain of delegation" in parliamentary democracies (Strøm, 2000).

In our study of the moral-hazard aspects of this relationship we are putting aside any possible adverse selection in the hiring of ministers. We view this as most appropriate, perhaps, in the UK setting where, as Strøm (2000) observed, "the British model greatly facilitates the prior parliamentary screening of cabinet members compared to the American one." Nevertheless, our analysis of the moral-hazard problem is not limited to the British system; it provides insights to the study of multi-party cabinets also and, although in our model we refer to a prime minister, the divergence of interests at the heart of our analysis is of equal relevance when the chief of the executive is the president.

The divergence of interests stems from a minister's desire to hold office. ${ }^{2}$ Following Diermeier, Keane, and Merlo's (2005) suggested “exploration of politicians' motivations in the context of their political careers" we find that self-interested career concerns may lead to reduced political 
activism. This reduced activism becomes a concern for the prime minister, since it impacts upon her ability to successfully implement the government's policy agenda. This turns our attention toward the cabinet management strategy of the prime minister.

To offset a minister's career concerns, and hence provide incentives for political activism, we study a prime minister's "protection policy." In our model a minister may be in one of two situations: (i) he is known for his involvement in a scandal, in which case he is tainted; or (ii) he has a scandal-free record, in which case he is clean. If a tainted minister is hit by a scandal, we assume that political pressures are so great that the prime minister is forced to fire him; this is a "two strikes and out" rule. If a clean minister is hit by a scandal, however, then the prime minister chooses whether to fire him or protect him. A protection policy, then, is the probability with which a "first strike" minister is protected following a scandal. We also consider the ability of a tainted minister to recover from a scandal. Over time scandals are forgotten and so a tainted minister who experiences a recovery returns to a state in which his record is clean.

A problem for the prime minister is that if a tainted minister is protected then, since the public are always willing to believe the worst, the executive's popularity falls; protection is costly. Nevertheless, some protection may be optimal if it helps resolve the moral-hazard problem. A minister realizes that he is less likely to be fired following a scandal, and therefore is more willing to implement risky policies. This is, in economic parlance, a substitution effect: the minister faces an incentive to substitute away from the status quo, and toward the executive's objectives.

There is, however, a second effect. A minister who is tainted by scandal realizes that he will not be protected from any further scandal, following the "two strikes and out" rule. He might "keep his nose clean" in the hope that the scandal is subsequently forgotten. Enhanced protection for clean ministers will increase the value of ministerial careers. This, in turn, increases the incentive for a tainted minister to keep his nose clean. This is, in economic parlance, an income effect: the 
minister faces an increased incentive to keep his (now more valuable) job, and biases toward safe policies. Increased protection can increase career concerns and reduce activism.

A sporting example illustrates these effects. A soccer player receives a yellow card for a misdemeanor; a second results in dismissal. A cautioned player knows that if he commits a further foul he may be sent off and so will be more careful in his challenges on the opposition. The coach has an incentive to substitute him with a "clean" replacement from the bench since (i) there is the risk that the team will be left a player short and (ii) the cautioned player may play over-cautiously. However, if all yellow-carded players are immediately replaced then even clean players will be cautious since a single yellow card will lead to them being substituted. How a coach deals with those players who are cautioned is thus an important element of his overall strategy.

When we consider these effects in our ministerial setting, we find that a clean minister responds to higher rates of both protection and recovery with increased activism. However, the opposite holds for a tainted minister. Our message is that the income effect can limit the prime minister's desire to offer protection. More generally, the effect of other parameters, such as a minister's exogenous exposure to scandals, can have surprising consequences that feed via the income effect into a minister's career concerns.

Our analysis explores the circumstances under which a prime minister finds it optimal to offer some protection to her ministers. This comes at a cost: the prime minister's popularity is adversely affected by the presence of tainted ministers in her cabinet. This cost can destroy the credibility of protection in a one-shot game, since a prime minister faces a short-run temptation to renege on her promise to protect and give in to resignation calls. Thus, whilst a "protection policy" offers a resolution to the moral hazard problem, such a policy may lack credibility. In repeated interactions with cabinet members, however, the prime minister might establish a reputation for protecting ministers and thus induce higher activism levels. To understand the forces involved, suppose that a prime minister pledges protection to an individual minister. If she 
were to renege on her promise in the face of a scandal, then the minister's replacement would not believe her in the future; the prime minister will lose her credibility. This provides the prime minister with an incentive to keep her promises.

Of course, if the short-term incentive to fire is too great, then the protection policy fails. A possible resolution is to exploit the interaction with multiple cabinet members. If a failure to protect a minister is observed by his cabinet colleagues, the prime minister must compare the short-term gain from firing him with the loss of her reputation across the entire cabinet. With a large cabinet, this suggests that the long-term loss of reputation will outweigh short-term temptations, restoring credibility. The industrial economists (Bernheim and Whinston, 1990) who developed this idea referred to it as "multi-market contact." They studied collusive oligopolists interacting in more than one market. Collusion is sustained because if a firm cheats (perhaps by cutting its price) in one market, then it is punished (via a retaliatory price war) in multiple markets. Here the analogy is that cheating on an agreement with one minister is punished by the entire cabinet. The pooling of the various principal-agent relationships in the cabinet yields what we might call "multi-minister contact."

Unfortunately, this mechanism can fail. Given that a prime minister loses her reputation by firing a minister, she may as well fire all tainted ministers; with her reputation in tatters, she will go all out and reshuffle the entire cabinet. This is important, because there is always the chance that the cabinet will reach a situation in which a large fraction of its members are tainted. In this circumstance, her short-term temptation is the gain from firing all tainted ministers. The prime minister will yield to this incentive and the attempt to maintain her reputation will unravel.

Nevertheless, there are circumstances when a cabinet-wide reputation leads to credible protection. Perhaps surprisingly, a necessary condition is the heterogeneity of ministers. For some ministers, the prime minister's temptation to fire would, absent the collective reputation in the cabinet, be too strong, whereas for others it would not. By pooling these effects, the prime minister uses the 
reputational slack in one relationship to compensate for the lack of credibility in another. An equivalent mechanism was exploited by Bernheim and Whinston (1990) in their work; they demonstrated that multi-market contact can enhance collusion when the markets have different characteristics.

This provides insight into how cabinet composition affects the ability of a prime minister to establish a credible protection policy. In a scenario in which she can select different types of ministers (which we do not model explicitly here) one might expect her to choose high-recovery types only. Other things equal, such high recovery types are more active; it follows that they are also cheaper to protect. Perhaps surprisingly, these are the types of ministers that lead to credibility problems. Once such a minister is tainted, they will sit tight in the hope that a scandal blows over. Such ministers are essentially "sitting ducks," and the prime minister faces a strong temptation to fire them. Indeed, if the cabinet consists of a large enough pool of sitting ducks, then the prime minister's commitment to a protection policy will unravel due to her short-term incentive to re-shuffle. However, the inclusion of low-recovery types can help mitigate this incentive. In contrast to higher-recovery types, when low-recovery ministers are hit by scandal they increase their activism. A shortened expected tenure leads these ministers to focus on their achievements in the short-run, and they thus adopt a "live for today" attitude since they have no hope that the effect of the scandal will abate. For that reason, they will soon be hit by a second scandal and will depart. The prime minister has a reduced temptation to fire such ministers.

\section{A Simple Model of Scandal And Recovery}

We begin our formal analysis by examining the behavior of a single minister and his relationship with the prime minister. At each moment in (continuous) time, the minister controls a single variable: his political activism $a \geq 0$, interpreted as the number of new policy initiatives that he pursues. In the course of his activities the minister faces a risk of policy failures and hence 
resignation calls following a political scandal. There is a large empirical literature that studies the termination of governing coalitions, where hazards stem from exogenous events and institutional features. For instance, Diermeier and Stevenson $(1999,2000)$ found that the hazard rate of termination increases as the next mandatory election approaches, adding some support to the theoretical work of Lupia and Strøm (1995). Here, however, an individual's exposure to policy failures is not an exogenous "critical event" in the sense of Browne, Frendreis and Gleiber (1984, 1986), but rather is related to his endogenous choice of activism. Formally, the hazard rate $\lambda(a)$ of scandals is an increase, convex, and continuously differentiable function of $a$.

Prior to the arrival of a scandal, a minister is clean; following a scandal, he becomes tainted. A minister remains tainted until the scandal is forgotten. Once amnesia sets in the minister recovers to a clean position. This reflects the view that, over time, scandals blow over and stories disappear from the media. We might expect the media and political opponents to keep longer records of a minister's performance. Our aim here, however, is to capture the idea that ministers are able to weather the storm. Formally, the hazard rate of a minister's recovery is $\beta$. Allowing $\beta$ to depend on activism would not change the results in any important way.

The prime minister makes hiring and firing decisions contingent only upon the arrival of scandals and the minister's current reputation; she cannot directly dictate the activism of her ministers. This is the source of the moral-hazard problem, since behavior can only be influenced via a reaction to scandals. ${ }^{3}$ When a scandal hits an already-tainted minister, the resignation pressures are irresistible. Such a minister is automatically fired, yielding a "two strikes and out" firing rule. When a clean minister is hit by scandal, however, the prime minister may (i) protect the minister, so that he becomes tainted; or (ii) fire him, in which case a replacement maintains the clean reputation of the cabinet post. We restrict attention to the following protection policy. When a clean minister is hit by a scandal, the prime minister protects him with probability $p$. Equivalently, he is forced to quit with probability $1-p$. Thus, all else equal, an increase in $p$ 
reduces the exposure of a clean minister to the loss of his job following a scandal. A tainted minister, on the other hand, is fully exposed. A benchmark is a "squeaky clean" regime with $p=0$, where any minister (clean or tainted) is automatically fired following a resignation call.

We turn to payoffs. A minister enjoys a flow benefit $v(a)>0$ from his job, and a zero flow benefit once fired. ${ }^{4}$ This benefit from cabinet membership is single peaked and maximized by $\bar{a}>0$, which represents the ideal level of political activism that a minister would choose if he faced no risk of a forced resignation. The minister discounts the future at a rate of $\gamma$. The prime minister enjoys a flow benefit $w(a)>0$ from the activism of her minister, and discounts the future at rate $\hat{\gamma}$; she cannot be fired, and hence such discounting captures the limits to her political tenure. Her flow benefit is single peaked around $\bar{a}$, and hence the political actors agree on the desired degree of activism; there is no direct conflict of political preferences. When a minister is tainted, however, the prime minister's flow payoff falls by $\delta \geq 0$ due to the reduced popularity of her government. Given this specification, we see an immediate conflict of interest. When a scandal arrives, the prime minister prefers to replace the minister and avoid the penalty $\delta$. In contrast, even if he dislikes being the subject of resignation calls, the minister would rather keep his job.

\section{POLICY ACTIVISM}

We now fix the protection $p$ offered by the prime minister, and calculate the policy activism choices of clean and tainted ministers, labeled $a_{H}$ and $a_{L}$ respectively. Absent other considerations, a minister would select the ideal activism $\bar{a}$. Of course, lowering activism will reduce the arrival rate of damaging scandals and so increase the longevity of his career.

To assess the impact of a minister's career concerns, we must calculate the value of his job to him. We write $V_{H}$ for the present discounted value of a clean minister's career, and $V_{L}$ for the value of a tainted minister's career. If a tainted minister is fired then he loses $V_{L}$. Similarly, if a clean minister is hit by a scandal and resigns, then he loses $V_{H}$. If he is protected, however, then he 
loses only $V_{H}-V_{L}$. Finally, if a tainted minister recovers (so that any previous scandal is forgotten) then he gains $V_{H}-V_{L}$. Activism changes the arrival rate of scandals, and hence the likelihood of one of these changes; this is the essence of the career-concerns effect.

To move further, we need to compute $V_{H}$ and $V_{L}$. We first consider a clean minister. Given that his job has value $V_{H}$ and that he discounts the future at rate $\gamma$, his net flow payoff must be $\gamma V_{H}$. Part of this is the direct benefit $v\left(a_{H}\right)$ derived from holding office. However, the net payoff also incorporates two status-changing possibilities: (i) the minister may be hit by a scandal and forced to resign; or (ii) he may be hit by a scandal and then protected. Scandals arrive with a hazard rate of $\lambda\left(a_{H}\right)$, and the subsequent dismissal and protection decisions occur with probabilities $1-p$ and $p$ respectively. Collecting these elements together,

$$
\underbrace{\gamma V_{H}}_{\text {net flow payoff }}=\underbrace{v\left(a_{H}\right)}_{\text {flow benefit }}-\underbrace{\lambda\left(a_{H}\right)}_{\text {scandal arrival }} \times \underbrace{[\underbrace{(1-p) V_{H}}_{\text {(i) fired }}+\underbrace{p\left(V_{H}-V_{L}\right)}_{\text {(ii) protected }}]}_{\text {status changed by a scandal }}
$$

We can perform a similar calculation for a tainted minister. His flow benefit $v\left(a_{L}\right)$ from holding office is combined with two status-changing events: (i) he is hit by a scandal and automatically fired; and (ii) he recovers from the previous scandal, and his reputation is restored. For the first possibility, scandals arrive at rate $\lambda\left(a_{L}\right)$ and involve the complete loss of the minister's career at a cost of $V_{L}$. For the second, recovery arrives at a rate of $\beta$ and leads to a gain of $V_{H}-V_{L}$. Hence:

$$
\underbrace{\gamma V_{L}}_{\text {net flow payoff }}=\underbrace{v\left(a_{L}\right)}_{\text {flow benefit }}-\underbrace{\lambda\left(a_{L}\right) \times V_{L}}_{\text {(i) scandal then fired }}+\underbrace{\beta \times\left(V_{H}-V_{L}\right)}_{\text {(ii) recovery }}
$$

The expressions (1) and (2) jointly determine the values $V_{H}$ and $V_{L}$ of clean and tainted ministerial careers, given their activism choices. Straightforward calculations confirm that $V_{H} \geq V_{L}$; a minister prefers to be free from scandal. Furthermore, an increase in the recovery rate will increase the value of both clean and tainted careers since it helps to restore a minister's status. Similarly, enhanced job security from increased protection increases career values. 
We may now characterize activism choices. We begin with a clean minister. By raising activism, he gains a marginal benefit $v^{\prime}\left(a_{H}\right)$ while holding office, but at the cost of a marginal increase $\lambda^{\prime}\left(a_{H}\right)$ in the arrival rate of a scandal. The net loss from a scandal is $V_{H}-p V_{L}$; he loses the value of his clean career $V_{H}$, but with probability $p$ he is protected by the prime minister and so retains the value $V_{L}$ of a tainted career. His choice of $a_{H}$ will just balance these two effects: ${ }^{5}$

$$
v^{\prime}\left(a_{H}\right)=\lambda^{\prime}\left(a_{H}\right) \times \underbrace{\left(V_{H}-p V_{L}\right)}_{\text {career concern }} .
$$

Since the clean minister has a real concern for his career status (that is, $V_{H}>p V_{L}$ ) he will bias his activism below the otherwise-ideal level, so that $a_{H}<\bar{a}$.

A tainted minister faces a similar problem. Increased activism yields a marginal benefit of $v^{\prime}\left(a_{L}\right)$ but an increased risk of $\lambda^{\prime}\left(a_{L}\right)$. When tainted, a minister is forced to resign following a second scandal (two strikes and he is out) and he loses the entire value $V_{L}$ of his career. Hence:

$$
v^{\prime}\left(a_{L}\right)=\lambda^{\prime}\left(a_{L}\right) \times \underbrace{V_{L}}_{\text {career concern }}
$$

Once again, the minister's career concern $\left(V_{L}>0\right)$ limits his activism $\left(a_{L}<\bar{a}\right)$. Caution ensures that activism falls short of the ideal level agreed by him and the prime minister.

The expressions (1) - (4) give solutions for the activism choices and career values. Working directly with the various forces, however, we may identify the effects of protection and recovery.

A central insight is revealed by considering the effects on a tainted minister. He balances his flow benefit from holding office against his career concerns. The recovery rate and degree of protection do not enter directly into this trade-off; instead, they feed through the value of his career, captured by $V_{L}$. Any increase in this value will exacerbate his concerns and lead to reduced activism. ${ }^{6}$ Thus, for such a tainted minister, any changes in his environment will feed via what we may call an income effect. An increase in either the recovery rate or the degree of protection will raise $V_{L}$, 
and hence lead to a fall in $a_{L}$. Thus, if the prime minister seeks to enhance activism by protecting her ministers, then the income effect can work against her. It encourages tainted ministers to sit tight as they try to hold on to their (now more valuable) jobs.

The effects on a clean minister are more complex. The restraint on activism is captured by his career concern $V_{H}-p V_{L}$. This is influenced directly by a substitution effect: more protection will lead directly to a reduction in $V_{H}-p V_{L}$. This is as intended; a clean minister faces a greater chance of retaining a career following a scandal, and hence is willing to increase his activism. On the other hand, income effects are also present. An increase in protection (and also in recovery) will tend to increase both $V_{H}$ and $V_{L}$. In particular, the income effect of an increase in the value of a clean minister's career (raising $V_{H}$ ) will actually reinforce career concerns.

Given the substitution effect and two conflicting income effects the effect of protection and recovery on the activism of a clean minister seems ambiguous. Fortunately, we can identify the net influence of these factors. Intuitively, an increase in recovery has most impact on the career of a tainted minister, and hence $V_{H}-p V_{L}$ falls. Similarly, the substitution effect of protection ensures that the net effect is to lower the minister's career concern. Drawing this analysis together, we obtain the following proposition which identifies the overall impact of protection and recovery.

Proposition 1. A minister will be less active than the agreed ideal level. An increase in either protection or recovery increases the activism of a clean minister, but reduces that of a tainted minister. A tainted minister will be less active then a clean minister, and hence will "sit tight."

At first blush, the effect of protection on a clean minister seems uncontroversial since the prime minister's safety net allows him to be more active. As we can see, the total effect is somewhat more subtle as it feeds through both income and substitution effects. The presence of income effects explains the effect on the tainted minister. He finds the position as a clean minister to be more valuable, and hence is tempted to "sit tight" and wait for a recovery. 
Of course, the secondary effect on tainted ministers is not present when there is no chance of recovery; a tainted minister can never win back a clean reputation and hence changes in protection do not influence him. Hence increased protection unambiguously increases political activism so long as recovery is impossible. This will be the case if scandals are never forgotten. A message from our analysis is that, while our model is extremely simple, the effects of protection and recovery can be subtle. The same is true when we turn attention to changes in the arrival rate of scandals. To move forward, we augment our model. A minister faces exogenous scandal exposure in addition to the risk generated by his activism, so that the arrival rate of scandals is $\bar{\lambda}+\lambda(a)$ for some background risk term $\bar{\lambda}>0$. The term $\bar{\lambda}$ may capture, for example, ministerial characteristics which make him more prone to scandal. Alternatively $\bar{\lambda}$ may capture political effects such as a predecessor's legacy which could come back to haunt the incumbent minister. An increase in $\bar{\lambda}$ has no direct influence on the relationship between activism and risk, so it must feed entirely through any income effects. An exogenous increase in exposure to scandals will reduce the value of a minister's career, whether clean or tainted. For a tainted minister, it is solely an income effect that drives his activism choice and we will see an increase in his activism. A clean minister's situation is more complex, since his career concern $V_{H}-p V_{L}$ combines two income effects. Nevertheless, we can establish conditions under which he too reacts to an exogenous increase in the risk of scandals by engaging in more, rather than less, risky activism.

Proposition 2. An exogenous increase in exposure to political scandals will enhance the activism of a tainted minister. It will also enhance the activism of a clean minister so long as protection is low. (A sufficient condition for this to be true is $p<\frac{1}{2}$.) However, for higher levels of protection, and when the recovery rate is high, a clean minister will reduce his activism.

The value of a tainted minister's career falls with increased exposure, and hence he "lives for today." This effect dominates whenever the the prime minister insists on a "squeaky clean" 
cabinet. A clean minister never becomes tainted (a scandal results in an automatic dismissal) and so, in turn, recovery and protection play no role. The exogenous exposure to scandals, however, still has an effect. Increased exposure always results in more, not less, activism.

The implications are interesting. Suppose that the exogenous scandal exposure is high, perhaps because of past policy initiatives in a minister's department. This will encourage him to take more risks in the future. Similarly, a history of caution will lead to further caution. This suggests that both high levels of policy activism and an adherence to a status quo are self-reinforcing.

The characterization of a squeaky clean cabinet is very simple, and so for specific functional forms we may calculate explicit solutions. To do this, we set $\lambda(a)=a$ so that the arrival rate of scandals is simply $\bar{\lambda}+a$, and adopt a quadratic-loss specification for the minister's flow benefit:

$$
v(a)=\bar{v}-\frac{\theta(\bar{a}-a)^{2}}{2}
$$

The term $\bar{v}>0$ represents the simple trappings of office. This flow benefit might include the minister's remuneration or the prestige of his position. It provides a simple and direct career concern. The quadratic-loss term represents the penalty from operating below the ideal level of political activism. The parameter $\theta$ is then the strength of the minister's political convictions.

Proposition 3. Under the quadratic-loss specification of (5) and in a squeaky clean cabinet, a minister's activism increases with: the ideal level of activism; the discount rate; any exogenous exposure to scandals; and political convictions. Activism decreases with the trappings of office. If the trappings of office are too large (if $\bar{v}>2 \bar{a} \theta(\gamma+\bar{\lambda})$ ) the minister will choose zero activism.

Proposition 3 confirms the "live for today" effect. Activism also increases with a minister's impatience and is influenced by a trade-off between a desire to hold office and political convictions. In summary, activism in a squeaky clean cabinet is high when a minister is impatient, exogenously exposed to scandals, and cares relatively little for the trappings of office. 


\section{The Prime Minister’s Protection Policy}

We now study the design of the prime minister's protection policy. Protection encourages the activism of clean ministers. Too much protection, however, and the cabinet becomes populated with sitting ducks. These tainted ministers eschew initiatives while waiting for recovery.

To make progress we calculate the value of the prime minister's relationship with her minister; $W_{H}$ for a clean minister and $W_{L}$ for a tainted minister. Given the discount rate $\hat{\gamma}$, a clean minister generates a net flow payoff of $\hat{\gamma} W_{H}$. There is a direct benefit of $w\left(a_{H}\right)$ from his activism.

However, scandals arrive at a rate of $\lambda\left(a_{H}\right)$. Following such a scandal, the prime minister protects the minister with probability $p$; this reduces the relationship's value by $W_{H}-W_{L}$. Hence,

$$
\underbrace{\hat{\gamma} W_{H}}_{\text {net flow payoff }}=\underbrace{w\left(a_{H}\right)}_{\text {flow benefit }}-\underbrace{\lambda\left(a_{H}\right)}_{\text {scandal arrival }} \times \underbrace{[p \times \underbrace{\left(W_{H}-W_{L}\right)}_{\text {loss following protection }}]}_{\text {effect of a scandal }} .
$$

When the minister becomes tainted, the flow benefit falls for two reasons: first, the direct penalty from protecting a tainted minister; and second, reduced activism (following Proposition 1). If the minister recovers or he is hit by a second scandal (invoking the "two strikes" rule, so that the minister quits) then the prime minister will gain $W_{H}-W_{L}$. Hence,

$$
\underbrace{\hat{\gamma} W_{L}}_{\text {net flow payoff }}=\underbrace{w\left(a_{L}\right)-\delta}_{\text {flow benefit minus penalty }}+\underbrace{\left(\beta+\lambda\left(a_{L}\right)\right)}_{\text {scandal or recovery }} \times \underbrace{\left(W_{H}-W_{L}\right)}_{\text {restored cleanliness }} .
$$

We can combine Equations (6) and (7) to obtain solutions for $W_{H}$ and $W_{L}$. Although we omit the details here, $\hat{\gamma} W_{H}$ and $\hat{\gamma} W_{L}$ are simple weighted averages of $w\left(a_{H}\right)$ and $w\left(a_{L}\right)-\delta$. (The explicit solutions are derived in the Appendix.)

Given that a newly appointed minister begins with a clean reputation, the prime minister chooses the level of protection $p$ to maximize $W_{H}$ (or, equivalently, $\hat{\gamma} W_{H}$ ). The activism choices will, of course, be made endogenously by her minister following our earlier analysis. 
We now identify the effects of increased protection. Since $\hat{\gamma} W_{H}$ is a weighted average of $w\left(a_{H}\right)$ and $w\left(a_{L}\right)-\delta$, protection will affect these two flow payoffs and also their relative weighting. From Proposition 1, there are two flow-payoff effects from increased protection: (i) increased activism of a clean minister; and (ii) reduced activism of a tainted minister due to the income effect. This second effect (a tainted minister will sit tight) means that the prime minister dislikes having a tainted minister in her cabinet even when there is no direct penalty from protecting him. There are, however, replacement effects that change the composition of a cabinet. As protection is increased, the cabinet is more likely to contain tainted ministers. There are three reasons for this: (iii) increasing protection directly increases the transition of ministers from a clean state to a tainted one, simply because scandalized ministers are more likely to be retained; (iv) this effect is exacerbated by the increase in the activism of clean ministers, and hence an increased risk of their involvement in scandals; and (v) tainted ministers will, following an increase in protection, tend to sit tight, so that they are less likely to experience a second scandal, depriving the prime minister of an excuse for sacking them. Notice that all of these replacement effects (iii)-(v) shift weight away from the desirable flow payoff from the relationship with a clean minister.

In summary, protection succeeds in raising activism, but only for clean ministers; all other effects work against the prime minister. This suggests that it might be optimal to offer no protection. We explore the conditions under which this is not the case. Most immediately, we focus attention on circumstances where some or all of the negative effects are no longer present. One such situation is when recovery is impossible. This means that the actions of a tainted minister are unaffected by the protection policy (he can never restore his reputation and hence benefit from the protection) and effects (ii) and (v) disappear. The prime minister asks whether the benefits of clean-minister activism (i) exceed the increased incidence of tainted ministers from (iii) and (iv).

A second situation involving a simplified trade-off is when the prime minister begins with a squeaky-clean cabinet. That is, we imagine an increase in protection beginning from $p=0$. This 
allows us to pinpoint the conditions under which a prime minister would wish to introduce a protection policy. Now only two effects matter. To see why, notice that when protection is close to zero, a prime minister rarely retains a tainted minister, and hence hardly feels the effect of the reduced activism of tainted ministers following an increase in protection; effect (ii) disappears. Similarly, effect (v) disappears: while tainted ministers tend to sit tight, there are very few of them when protection is close to zero. Finally, effect (iv) disappears: clean ministers are more likely to experience scandals, but again they are very rarely protected and hence this effect is hardly felt. (Technically, (ii), (iv), and (v) are only second-order effects at $p=0$.)

Starting from a squeaky clean cabinet, the introduction of protection involves only effects (i) and (iii). Effect (i) is the desired increase in activism. Effect (iii) is the increased risk that the value of the relationship declines; the minister may be retained following a scandal, thus reducing the value of the relationship by $W_{H}-W_{L}$. When protection is close to zero, however, the activism choices of clean and tainted ministers will be approximately the same. Hence the gap $W_{H}-W_{L}$ will be entirely determined by the direct penalty from protecting a scandalized minister.

Proposition 4. Starting from a squeaky clean cabinet, the introduction of protection is worthwhile if and only if the direct penalty from protecting a tainted minister is sufficiently low. If this direct penalty is zero, then it is always optimal to introduce some protection.

This proposition reveals that while the effects of protection can be quite complicated, they are somewhat simpler when we consider the first step toward a protection policy. We can obtain even sharper results by adopting specific functional forms. We allow the hazard rate of scandals to be linear in activism and choose a quadratic-loss specification for the minister, following Equation (5). We adopt a similar specification for the prime minister:

$$
w(a)=\bar{w}-\frac{\psi(\bar{a}-a)^{2}}{2} .
$$


Here the parameter $\psi$ reflects the prime minister's desire to pursue activist policies.

Proposition 5. Under the quadratic-loss specifications of Equations (5) and (8) and beginning from a squeaky clean cabinet, the introduction of a protection policy is optimal if and only if $\delta \leq \psi \times R$, where $R$ is a term that increases with $\hat{\gamma}, \beta$, and $\bar{v}$, but decreases with $\bar{\lambda}$ and $\theta$. That is, the introduction of protection is more likely to be optimal when: the prime minister places a large weight on political activism; the recovery rate is high; and when the minister's trappings of office are high. It is less likely to be optimal when: the penalty from protection is large; there is a high exogenous rate of scandal arrival; and when the minister has high political convictions.

Protection is worthwhile when scandals are not too painful and when activism is important. When the recovery rate is high, tainted ministers recover quickly and hence a limited amount of protection is not too costly. When there is a high exogenous risk of scandals, the costly act of protection must be taken more often. In summary, a prime minister will offer protection when ministers are less likely to be hit by scandal and when they find it easy to recover.

Proposition 5 establishes the conditions under which the prime minister wishes to introduce protection. As protection rises, however, she will endure the presence of tainted ministers. This means that their activism starts to become important, and effects (ii), (iv) and (v) start to be felt.

To illustrate this, we study some numerical examples. In Figure 1(a) we plot $W_{H}$ against protection for different values of $\beta$. Whereas Proposition 5 shows the that the introduction of protection is more likely to be beneficial when the recovery rate is high, the optimal level of protection can decrease with $\beta$. Evaluating the income effect on a tainted minister provides the correct intuition. Increased recovery enhances the value of a tainted minister's position; his activism decreases. One implication is that fewer tainted ministers exit the cabinet under the "two strikes" rule. We see then that recovery increases the relative cost of protection and, as such, the overall income effect of an increase in recovery drives down the level of protection. 
Figure 1 about here.

This highlights the dilemma which the prime minister faces when she has only one instrument, protection, available to her. She would like her clean ministers to be policy active. However she needs to ensure that too many ministers with clean reputations do not become scandalized. Lowering protection offsets the positive effect which an increase on recovery has on the activism of clean ministers. With tainted ministers the prime minister has the opposite concern. At the optimal protection level an increase in recovery reduces the policy activism of tainted ministers. These ministers are in effect "sitting ducks" who will sit tight in the hope that they recover from the scandal which has beset them. Thus an increase in recovery requires a corresponding decrease in protection to offsets this sitting-duck effect. Of course, the prime minister will not be overly concerned about the higher activism of tainted ministers since, under the two-strikes rule, these ministers can be replaced whilst maintaining an optimal protection policy for the cabinet.

Turning to the exogenous risk $\bar{\lambda}$, the intuition behind Proposition 5 is that more ministers become tainted and so protection should be lower; Figure 1(b) illustrates. There are income effects as well. The increase in exogenous risk reduces the value of careers and encourages a "live for today" attitude (Proposition 2). Hence there is less need to promote activism.

In Figure 1(b) the prime minister's payoff increases with the exogenous risk. This is true more generally. So long as protection is not too great (when $p<\frac{1}{2}$, for instance) Proposition 2 tells us that the activism of both clean and tainted ministers increases. An increase in the activism of a tainted minister is always a good thing. The increased activism of clean ministers, however, results in more tainted ministers. However, the prime minister can always offset this by reducing protection. For instance, following an increase in $\bar{\lambda}$ she could lower protection so that the activism of a clean minister falls back to its original level. Doing so, the net effect is to reduce the number of tainted ministers (protection is now lower, and tainted ministers are fired more quickly) while increasing the activism of tainted ministers (yielding political benefits). Hence a rise in 
exogenous risk is always beneficial. This rise coincides with an increase in ministerial turnover. High turnover could account for low levels of experience of British cabinet members (Huber and Martinez-Gallardo, 2004). Whereas there are many reasons for thinking that high turnover and low experience are undesirable, our analysis uncovers one positive effect: ministers live for today (by implementing policy) rather than looking after their long-term careers.

\section{CRedibility AND Collective Reputation}

Ideally (from her perspective) the prime minister would commit to her protection policy. Given that protection is directly costly and tainted ministers are less active, she will be tempted to renege on her promises and fire any minister following a scandal: she may lack credibility.

Despite this, a prime minister's concern for her reputation may restore this credibility. If she fires a transgressing minister when she promised to protect him, then she sacrifices her reputation with his replacement and with the remainder of her cabinet. Such a reputational mechanism might ensure that an implicit contract (in the sense of MacLeod and Malcomson $(1988,1989)$ ) with cabinet members is endogenously self-enforcing.

An objection is that ministers will observe the decision taken (fire or protect) but not its probability. This objection, however, is easily overcome. Our treatment of $p$ as the probability of protection is merely a convenient modeling device. We have in mind a regime where a prime minister promises to protect a minister so long as the clamor for his resignation is not too great, so that $p$ is the probability that the seriousness of a scandal falls below the prime minister's chosen threshold. ${ }^{7}$ Rather than model such a mechanism, we appeal to parsimony and assume that the level of protection $p$ exercised by the prime minister is observed.

Given that full commitment is impossible, we must consider what happens if the prime minister deviates. Since a deviation would arise from firing a scandalized minister to whom the prime minister had pledged protection, we suppose that, following this deviation, all cabinet ministers 
assume that the prime minister will revert to a squeaky clean hiring-and-firing policy. The prime minister will no longer face an incentive to protect tainted ministers. Thus we assume that if the prime minister deviates, and fails to offer sufficient protection for a scandalized minister, then she chooses to fire all tainted ministers from her cabinet. Essentially, she re-shuffles.

In summary, all ministers are initially clean. The prime minister states a protection policy. Cabinet members assume that the prime minister will follow her stated policy, unless she deviates. If she does, then all tainted ministers are fired. From that time onwards, any minister hit by a scandal is automatically fired, and hence the cabinet remains in a squeaky-clean state.

We now examine the incentives that the prime minister faces when contemplating a deviation. Following our earlier work, and for a given protection policy, the value of the prime minister's relationship with a minister is $W_{H}$ when he is clean and $W_{L}$ when he is tainted. If she deviates, however, then we need to calculate the value of the relationship under a squeaky clean regime. We write this value as $\tilde{W}$; it can be calculated by setting $p=0$ in our earlier analysis.

A first case to consider is when $W_{H}>W_{L}>\tilde{W}$. This is illustrated in Figure 2(a), where the optimal protection level is $p=1$, so that ministers are always forgiven when hit by a first scandal. There is no credibility problem: even when her minister is tainted, abandoning protection causes a drop in the value of the subsequent relationship with his replacement down to $\tilde{W}$.

Figure 2 about here.

The second (problematic) case involves $W_{H}>\tilde{W}>W_{L}$, and is illustrated in Figure 2(b), where $\tilde{W}>W_{L}$. When a minister is tainted, the prime minister faces an irresistible temptation to fire him: by continuing her relationship with him she obtains $W_{L}$; by discarding her reputation, however, and returning to a squeaky clean regime, she obtains $\tilde{W}$. The temptation $\tilde{W}-W_{L}>0$ leads her to cave in to resignation demands. Of course, cabinet members can anticipate this and hence they will not believe an initial promise of protection. 
The second case reveals that a prime minister can only maintain the credibility of a protection policy so long as $W_{L} \geq \tilde{W}$. For the specifications of Figure 2, one case leads to a credible policy whereas the other does not. More generally, this credibility constraint will limit the values of protection that the prime minister can offer. This analysis, however, is based upon our consideration of a bilateral relationship between the prime minister and a single cabinet member. By turning attention to the wider cabinet membership, we can assess whether a widespread collective reputation can assist the credibility of a protection policy.

To identify the properties of a multi-member cabinet, we begin by supposing that all ministers share the same preferences, exposure to scandals, and rates of recovery. The prime minister will then find it optimal to offer the same degree of protection to each minister. With $n$ ministers, the combined value of her relationship with her ministers when they are all clean is then $n \times W_{H}$.

Now suppose that one of her ministers experiences a scandal, and the prime minister is called upon to protect him. If she reneges, then she gains $\tilde{W}-W_{L}$ within the context of that individual relationship. However, if this deviation is observed by all other cabinet members, then they will no longer trust her. Her reputation will be in tatters, and she will suffer a loss of $(n-1) \times\left(W_{H}-\tilde{W}\right)$ from destroying her relationship with these ministers. So long as $(n-1) \times\left(W_{H}-\tilde{W}\right)>\tilde{W}-W_{L}$, the prime minister will face an incentive to keep her promises. This argument suggests that, so long as the cabinet is large, the incentive to maintain her reputation will stop the prime minister from caving in to the demand for a ministerial scalp. Multi-member cabinets might assist the credibility of a protection policy.

Unfortunately, this argument only works when there is a single tainted minister. A situation might arise in which all cabinet ministers are tainted. This situation will lead us back to an irresistible temptation for the prime minister to deviate. To see this, consider what happens when the $n$th minister experiences a scandal and demands protection. If the prime minister sacks him, then since her reputation will be in tatters, she may as well sack all tainted ministers. Put more 
succinctly, she re-shuffles her cabinet. This will result in a gain of $n \times\left(\tilde{W}-W_{L}\right)$, which is positive if and only if $\tilde{W}>W_{L}$. Of course, this is the configuration that caused the credibility problem in the first place. The problem, then, is that although the existence of a multi-member cabinet increases the penalty from breaking a promise, it also generates situations in which the temptation to renege is increased in turn. ${ }^{8}$

Proposition 6. The existence of a multi-member cabinet of identical ministers does not allow the prime minister to make a credible commitment to protection, when no such commitment could be made in the absence of such a cabinet.

Although the explanation is straightforward, we find this surprising. A large cabinet does not in and of itself produce the desired reputation effect which would allow credible protection.

We now turn to the case where there is a cabinet consisting of heterogenous ministers. Such heterogeneity occurs if, for example, the penalty which the prime minister incurs due to inactivity in one department is lower or higher than that incurred for another. Alternatively we might think of the recovery rate for one minister being lower or higher than for another minister, due perhaps to the relative seriousness of the scandals which stem from their respective portfolios.

To keep things simple, we consider a cabinet with two different portfolios $A$ and $B$, using two numerical specifications displayed in Figure 2. For these specifications, the ministers differ according to their recovery rates. (Similar insights emerge when we allow other parameters to differ.) Given that the ministers face different situations, we allow the prime minister to offer them different degrees of protection. (The argument continues to hold when we force her to offer the same level of protection to all ministers.) Inspecting Figure 2, she would wish to offer full protection to minister $A$ and protection of approximately $p=0.7$ to minister $B$. Now, the promise to $A$ is credible, since $W_{L}^{A}>\tilde{W}^{A}$. However, the promise to $B$ is not, since $W_{L}^{B}<\tilde{W}^{B}$. (We use superscripts to identify the individual ministers.) 
Can the prime minister combine her relationships with $A$ and $B$ and maintain credibility with both? It turns out that she can. The prime minister is most tempted to deviate when both members of the cabinet are tainted, for it is then that she can maximally gain by re-shuffling. She gains $\tilde{W}^{B}-W_{L}^{B}>0$ by abandoning her relationship with minister $B$, but loses $W_{L}^{A}-\tilde{W}^{A}>0$ from the valuable relationship with $A$. Combining these two effects, she will be willing to resist the temptation to deviate so long as $W_{L}^{A}-\tilde{W}^{A}>\tilde{W}^{B}-W_{L}^{B}$, or equivalently $W_{L}^{A}+W_{L}^{B}>\tilde{W}^{A}+\tilde{W}^{B}$. Inspecting Figure 2, we see that this inequality is satisfied, and hence the prime minister is able to resist temptation; her (jointly operated) protection policy is credible.

Proposition 7. The existence of a heterogeneous multi-member cabinet can allow the prime minister to make a credible commitment of protection to them all, even though there are some that she could not credibly protect individually.

With heterogeneity, the prime minister will show concern for the net effect of her actions. Effectively, she pools the credibility constraints of the ministerial team. When ministers are homogenous, this pooled constraint is identical to the constraint from the relationship with a single minister and we are left with Proposition 6. With heterogeneity, however, the prime minister can use the slack in one relationship to compensate for the lack of credibility in another. For our example, the presence of minister $A$ helps the provision of protection to minister $B$. It is interesting to note that in our example minister $A$ differs from $B$ by having a lower rate of recovery; in fact, for him $\beta=0$ so that there is no chance of recovery once he is hit by a scandal. Somewhat surprisingly, perhaps, the inclusion of a minister with a low rate of recovery (someone who we might regard as a risky prospect) can assist the protection of a high-recovery minister. Thinking about the income effects helps to explain this. For minister $B$, the possibility of recovery means that he sits tight once tainted. This provides the prime minister with a strong temptation to shoot a sitting duck; it is the inactive nature of high-recovery ministers that cause 
problems for the credibility of a protection policy. There is no such a problem for minister $B$ since when tainted he lives for today and hence the prime minister is happy to stick by her word.

\section{CONCLUDING REMARKS}

We have explored how a prime minister may use the hiring and firing of ministers, to pursue political objectives. Both she and her ministers are keen to be policy active. Such activism, however, creates the risk of resignation calls. Ministers face a moral-hazard problem: they shy away from activism in order to avoid the scandals that would cost them their jobs. We have focused on the role of the prime minister in protecting her ministers from such consequences of their activism. A protection policy can provide incentives for ministers to take risks.

We view this aspect of the relationship between the prime minister and her executive as a crucial factor in ministerial careers. As such our model fits into a broader literature which examines the effect of institutions on the quality of the political elite. As noted by Caselli and Morelli (2004), a preponderance of a "bad politicians" affects the value of a career such that talented candidates exempt themselves from public life. Besley and Case (1995) looked at the effect of elections as institutional mechanisms which can mitigate against this effect, whilst Dal Bó and Di Tella (2003) focused on the role of parties as a means of protection for "good politicians". Our model is the first we know of that formally analyzes the hiring and firing decisions which are made by the chief of the executive and its effects on the value of ministerial careers.

We obtained some surprising results. In our model the political preferences of the prime minister and her ministers are aligned. However, whereas the promise of protection enhances the activism of those who are free from scandal, the same promise encourages tainted ministers to sit tight. This is due to the income effect of protection upon career concerns. Anything that increases the value of a career will make a minister more sensitive to the loss of his job. Protection can do just that. In contrast, a shorter expected job tenure will focus a minister's attention on the short run, so 
that he "lives for today." Thus, ministers who suffer from an exogenously higher risk of scandal or who have past exposures and have little chance of recovery are more likely to be policy active.

This insight sheds light onto two issues. Firstly, we observe that some ministers appear to be dramatically more exposed to scandals than others. Most commentators attribute this to personality traits of the ministers involved. The income effect demonstrates that a small tendency toward scandal can lead to greater exposure. The initial tendency leads to a shortened expected tenure, and thus increased activism, reinforcing a minister's exposure and subsequent resignation. Secondly, a widely held view is that the incumbents of some departments have a higher exposure than incumbents of others. For example, the British Home Office is often seen as a ministerial graveyard with many promising careers having come to a premature end due to failed policy initiatives. Most commentators have treated this effect as a structural feature of the British cabinet system of government. Here, however, the income effect can provide new insights. If the incumbent in a department is policy active, then his successor faces an increased risk of subsequent policy failures. Given that the initiatives of his predecessor may come back to haunt him, the successor faces a lower expected tenure and adopts a "live for today" attitude by hastening the implementation of policy reforms. In summary, we expect a department's reputation for policy activism and the associated policy failures to be self-reinforcing.

The income effect also illuminates the prime minister's protection policy, which may vary with other parameters in surprising ways. An increase in the ability of ministers to recover from scandal decreases the optimal level of protection which is offered. The protection increases with a minister's exogenous exposure to scandal. Our explanations highlight the effects of the protection policy on the transition rates between the minister's states. For example, since recovery increases the activism of clean ministers and decreases that of tainted ministers the prime minister is concerned with what we call the "sitting duck" effect. An increase in the recovery rate may turn the cabinet into a sitting-duck pond; a reduction in the level of protection can offset this effect. 
In addition to addressing the moral-hazard issue in cabinet governance we have also addressed the credibility of a prime minister's protection policy. Since the political preferences of the actors are aligned, one might think that a cabinet would not play much of a role. This is not the case however, since the existence of a multi-member cabinet allows the prime minister to credibly commit to her protection policy. This, in turn, allows the cabinet to move toward fulfilling its policy objectives. In sum, the existence of a cabinet leads to behavior which would be different to that which would be observed in the absence of such a cabinet. ${ }^{9}$

This issue is somewhat subtle, in that a multi-member cabinet is of use only when ministers are heterogeneous. This is an interesting application of the multi-market contact idea (Bernheim and Whinston, 1990) which has, so far, received little attention in the political science arena. A notable exception is a recent paper by Stasavage and Guillaume (2002), who investigated conditions which help sustain monetary unions. They argued (p. 121) that a "fear of losing the benefits from parallel agreements in the areas of trade, aid or security can dissuade even a government with strong preferences for looser monetary policy from exiting." This idea was described as "linkage politics" by Lohmann (1997). Drawing upon this idea, we offer an alternative to the traditional view of the cabinet, which is that it acts as a check on the ambitions of individual ministers (Palmer, 1995).

The institutional setting for our model does not take into account the partisan composition of the governing coalition. Neither do we consider here the effects of interaction between ministers in cabinet government. ${ }^{10}$ In particular we do not consider how the scandals of other ministers may affect activism and subsequent protection levels. Whilst these elements do not figure in our model, we do think that the key effects to which we draw attention, namely the importance of income effects when considering the prime minister's protection policy and the role of the cabinet in enforcing protection, are relevant when considering these alternative institutional frameworks. 


\section{REFERENCES}

Bernheim, B. Douglas and Michael D. Whinston. 1990. "Multimarket Contact and Collusive Behavior.” RAND Journal of Economics 21(1):1-26.

Besley, Tim and Anne Case. 1995. "Incumbent Behaviour: Vote-Seeking, Tax-Setting and Yardstick Competition.” American Economic Review 85(1):25-45.

Browne, Eric C., John P. Frendreis and Dennis W. Gleiber. 1984. “An 'Events' Approach to the Problem of Cabinet Stability." Comparative Political Studies 17(1):167-97.

Browne, Eric C., John P. Frendreis and Dennis W. Gleiber. 1986. “The Process of Cabinet Dissolution: An Exponential Model of Duration and Stability in Western Democracies." American Journal of Political Science 30(3):628-50.

Caselli, Francesco and Massimo Morelli. 2004. "Bad Politicians.” Journal of Public Economics 88(3-4):759-82.

Dal Bó, Ernesto, Pedro Dal Bó and Rafael Di Tella. 2004. "Plata o Plomo? Bribe and Punishment in a Theory of Political Influence." forthcoming in the American Political Science Review .

Dal Bó, Ernesto and Rafael Di Tella. 2003. “Capture by Threat.” Journal of Political Economy 111(5):1123-54.

Dewan, Torun and Keith Dowding. 2005. "The Corrective Effect of Ministerial Resignations.” American Journal of Political Science 49(1):46-56.

Diermeier, Daniel, Michael Keane and Antonio Merlo. 2005. “A Political Economy Model of Congressional Careers." American Economic Review 95(1):347-73.

Diermeier, Daniel and Randolph T. Stevenson. 2000. "Cabinet Terminations and Critical Events." American Political Science Review 94(3):627-40.

Diermeier, Daniel and Randy T. Stevenson. 1999. "Cabinet Survival and Competing Risks.” American Journal of Political Science 43(4):1051-68. 
Doig, A. 1993. “The Double Whammy: The Resignation of David Mellor, MP.” Journal of Parliamentary Affairs 46(2):167-91.

Huber, John D. and Cecilia Martinez-Gallardo. 2004. "Cabinet Instability and the Accumulation of Experience: The French Fourth and Fifth Republics in Comparative Perspective.” British Journal of Political Science 34(1):27-48.

Indridason, Indridi and Christopher Kam. 2005a. "Cabinet Reshuffles and Ministerial Drift." Working Paper.

Indridason, Indridi and Christopher Kam. 2005b. "The Timing of Cabinet Reshuffles in Five Westminster Parliamentary Systems.” Legislative Studies Quarterly XXX(3):327-63.

Krehbiel, Keith. 1993. "Where's the Party.” British Journal of Political Science 23(2):235-66.

Levy, Gilat. 2004. “A Model of Political Parties.” Journal of Economic Theory 115:250-77.

Lohmann, Susanne. 1997. “Linkage Politics.” Journal of Conflict Resolution 41(1):38-67.

Lupia, Arthur and Kaare Strøm. 1995. "Coalition Termination and the Strategic Timing of Parliamentary Elections." American Political Science Review 89(3):648-65.

MacLeod, W. Bentley and James M. Malcomson. 1988. "Reputation and Hierarchy in Dynamic Models of Employment.” Journal of Political Economy 96(4):832-54.

MacLeod, W. Bentley and James M. Malcomson. 1989. "Implicit Contracts, Incentive Compatibility, and Involuntary Unemployment.” Econometrica 57(2):447-80.

Morelli, Massimo. 2004. "Party Formation and Policy Outcomes under Different Electoral Systems." Review of Economic Studies 71(3):829-53.

Palmer, Mathew. 1995. “Towards an Economics of Comparative Political Organisation: Examining Ministerial Responsibility." Journal of Law, Economics and Organisation .

Stasavage, David and Dominique Guillaume. 2002. "When are Monetary Commitments Credible? Parallel Agreements and the Sustainability of Currency Unions.” British Journal of Political Science 32:119-46. 
Strøm, Kaare. 2000. "Delegation and Accountability in Parliamentary Democracies.” European Journal of Political Research 37(3):261-89.

Thies, Michael. 2001. "Keeping Tabs on Coaliton Partners: The Logic of Delegation in Cabinet Governments.” American Journal of Political Science 45(3):580-98. 


\section{OMITTED PROOFS}

Lemma 1. $V_{H} \geq V_{L}$. Both $V_{H}$ and $V_{L}$ are increasing in recovery $\beta$ and protection $p$.

Proof of Lemma 1. For a clean minister, the net flow payoff $\gamma V_{H}$ obtained via activism $a_{H}$ must exceed the flow payoff from switching to $a_{L}$. Hence $\gamma V_{H} \geq v\left(a_{L}\right)-\lambda\left(a_{L}\right)\left[V_{H}-p V_{L}\right]$. Subtracting the equality $\gamma V_{L}=v\left(a_{L}\right)-\lambda\left(a_{L}\right) V_{L}+\beta\left[V_{H}-V_{L}\right]$ we obtain

$$
\gamma\left[V_{H}-V_{L}\right] \geq \lambda\left(a_{L}\right) V_{L}-\beta\left[V_{H}-V_{L}\right]-\lambda\left(a_{L}\right)\left[V_{H}-p V_{L}\right]
$$

which may be re-arranged to yield $\left[\gamma+\beta+\lambda\left(a_{L}\right)\right] \times\left[V_{H}-V_{L}\right] \geq \lambda\left(a_{L}\right) p V_{L} \geq 0$. This implies that $V_{H}-V_{L} \geq 0$. To ascertain the effect of $\beta$, differentiate Equation (1) with respect to $\beta$ :

$$
\begin{aligned}
\gamma \frac{d V_{H}}{d \beta} & =\underbrace{\left\{v^{\prime}\left(a_{H}\right)-\lambda^{\prime}\left(a_{H}\right)\left[V_{H}-p V_{L}\right]\right\}}_{\text {zero from Equation (3) }} \times \frac{d a_{H}}{d \beta}-\lambda\left(a_{H}\right)\left[\frac{d V_{H}}{d \beta}-p \frac{d V_{L}}{d \beta}\right] \\
& =-\lambda\left(a_{H}\right)\left[\frac{d V_{H}}{d \beta}-p \frac{d V_{L}}{d \beta}\right] \Rightarrow \frac{d V_{H}}{d \beta}=\frac{p \lambda\left(a_{H}\right)}{\gamma+\lambda\left(a_{H}\right)} \times \frac{d V_{L}}{d \beta} .
\end{aligned}
$$

Hence $V_{L}$ is increasing in $\beta$ if and only if $V_{H}$ is. Next differentiate Equation (2):

$$
\begin{aligned}
\gamma \frac{d V_{L}}{d \beta} & =\underbrace{\left\{v^{\prime}\left(a_{L}\right)-\lambda^{\prime}\left(a_{L}\right) V_{L}\right\}}_{\text {zero from Equation (4) }} \times \frac{d a_{L}}{d \beta}-\lambda\left(a_{L}\right) \frac{d V_{L}}{d \beta}+\beta\left(\frac{d V_{H}}{d \beta}-\frac{d V_{L}}{d \beta}\right)+V_{H}-V_{L} \\
& \geq-\lambda\left(a_{L}\right) \frac{d V_{L}}{d \beta}+\beta\left(\frac{d V_{H}}{d \beta}-\frac{d V_{L}}{d \beta}\right) \Rightarrow \frac{d V_{L}}{d \beta} \geq \frac{\beta}{\gamma+\beta+\lambda\left(a_{L}\right)} \times \frac{d V_{H}}{d \beta},
\end{aligned}
$$

where the inequality follows from $V_{H} \geq V_{L}$. Combining this with the earlier equality,

$$
\frac{d V_{L}}{d \beta} \geq \frac{\beta}{\gamma+\beta+\lambda\left(a_{L}\right)} \times \frac{p \lambda\left(a_{H}\right)}{\gamma+\lambda\left(a_{H}\right)} \times \frac{d V_{L}}{d \beta}
$$

The first two terms on the right-hand side are both weakly positive and strictly less than 1 , and so the inequality cannot be satisfied if $d V_{L} / d \beta<0$. We conclude that $V_{L}$ is (weakly) increasing in $\beta$, and hence so is $V_{H}$. This establishes the second claim of the lemma. Turning to the third claim of 
the lemma, differentiate Equations (1) and (2) with respect to $p$ :

$$
\begin{aligned}
\gamma \frac{d V_{H}}{d p} & =-\lambda\left(a_{H}\right)\left[\frac{d V_{H}}{d p}-p \frac{d V_{L}}{d p}-V_{L}\right] \Rightarrow \frac{d V_{H}}{d p} \geq \frac{p \lambda\left(a_{H}\right)}{\gamma+\lambda\left(a_{H}\right)} \frac{d V_{L}}{d p}, \quad \text { and } \\
\gamma \frac{d V_{L}}{d p} & =-\lambda\left(a_{L}\right) \frac{d V_{L}}{d p}+\beta\left(\frac{d V_{H}}{d p}-\frac{d V_{L}}{d p}\right) \Rightarrow \frac{\beta}{d p}=\frac{\beta}{\gamma+\beta+\lambda\left(a_{L}\right)} \times \frac{d V_{H}}{d p},
\end{aligned}
$$

where we have used Equations (3) and (4) once more. If $V_{L}$ is strictly decreasing in $p$ then (10) ensures that $V_{H}$ is decreasing too and that $0>d V_{L} / d p>d V_{H} / d p$. This is inconsistent with (9). Hence $V_{L}$ must be increasing in $p$, implying in turn that $V_{H}$ must be increasing in $p$.

Lemma 2. A local change in $\beta$ or p leads to an an increase in $a_{L}$ if and only if it reduces $V_{L}$. In contrast, a local change in $\beta$ or p leads to an increase in $a_{H}$ if and only if it increases $V_{H}$.

Proof. From Equation (4) and the concavity of $v(a), a_{L}$ is increasing in a parameter if and only if $V_{L}$ is decreasing. Turning to the second claim, from Equation (3), $a_{H}$ is increasing in a parameter if and only if $V_{H}-p V_{L}$ is decreasing. Differentiation of Equation (1) yields

$$
\gamma \frac{d V_{H}}{d p}=-\left[\lambda\left(a_{H}\right) \times \frac{d\left[V_{H}-p V_{L}\right]}{d p}\right] \quad \text { and } \quad \gamma \frac{d V_{H}}{d \beta}=-\left[\lambda\left(a_{H}\right) \times \frac{d\left[V_{H}-p V_{L}\right]}{d \beta}\right]
$$

and so $V_{H}-p V_{L}$ is decreasing in a parameter whenever $V_{H}$ is increasing.

Proof of Proposition 1. For the first claim, $V_{L}>0$ and Equation (4) ensure that $v^{\prime}\left(a_{L}\right)>0$, so that $a_{L}<\bar{a}$. If $p=0$ then $a_{H}=a_{L}<\bar{a}$. If $p>0$ then $V_{H}>V_{L}$ and hence $V_{H}-p V_{L}>0$. Equation (3) then ensures that $a_{H}<\bar{a}$. The comparative-static claims follow from Lemmas 1 and 2: an increase in $\beta$ or $p$ will increase both $V_{H}$ and $V_{L}$ (Lemma 1); this results in a fall in $a_{L}$ and a rise in $a_{H}$ (Lemma 2). For the final two claims, notice that in the absence of protection $a_{H}=a_{L}$ since clean and tainted ministers both face a first-strike-and-out regime. The introduction of protection, corresponding to a rise in $p$, causes $a_{H}$ to rise and $a_{L}$ to fall, and so $a_{H}>a_{L}$. 
Proof of Proposition 2. The introduction of the exogenous scandal risk $\bar{\lambda}$ has no effect on Equations (3) and (4). Equations (1) and (2) hold when we replace $\lambda(a)$ with $\bar{\lambda}+\lambda(a)$. Finally, it is without loss of generality to set $\lambda(a)=a$. This is because $\lambda(a)$ is increasing in $a$, and so we are simply re-defining activism to correspond to the risk that it generates. (Since $\lambda(a)$ is convex, this change ensures that the minister's flow benefit remains a concave function of activism.) This formulation is adopted only to simplify the notation in our derivations.

Straightforward calculations ensure that $V_{L}$ and $V_{H}$ are decreasing in $\bar{\lambda}$. Equation (4) then implies that $a_{L}$ increases with $\bar{\lambda}$. Next, differentiate Equations (1) and (2) with respect to $\bar{\lambda}$ to obtain

$$
\begin{aligned}
\gamma \frac{d V_{L}}{d \bar{\lambda}} & =-V_{L}-\left(\bar{\lambda}+a_{L}\right) \frac{d V_{L}}{d \bar{\lambda}}+\beta\left[\frac{d V_{H}}{d \bar{\lambda}}-\frac{d V_{L}}{d \bar{\lambda}}\right], \quad \text { and } \\
\gamma \frac{d V_{H}}{d \bar{\lambda}} & =-\left[V_{H}-p V_{L}\right]-\left(\bar{\lambda}+a_{H}\right)\left[\frac{d V_{H}}{d \bar{\lambda}}-p \frac{d V_{L}}{d \bar{\lambda}}\right] .
\end{aligned}
$$

Straightforward but tedious manipulations then lead to the solutions

$$
\begin{aligned}
\frac{d V_{L}}{d \bar{\lambda}} & =-\frac{\beta\left[V_{H}-p V_{L}\right]+\left(\gamma+\bar{\lambda}+a_{H}\right) V_{L}}{\left(\gamma+\bar{\lambda}+a_{H}\right)\left(\gamma+\beta+\bar{\lambda}+a_{L}\right)-\beta p\left(\bar{\lambda}+a_{H}\right)}, \quad \text { and } \\
\frac{d V_{H}}{d \bar{\lambda}} & =-\frac{p\left(\bar{\lambda}+a_{H}\right)}{\gamma+\bar{\lambda}+a_{H}} \times \frac{\beta\left[V_{H}-p V_{L}\right]+\left(\gamma+\bar{\lambda}+a_{H}\right) V_{L}}{\left(\gamma+\bar{\lambda}+a_{H}\right)\left(\gamma+\beta+\bar{\lambda}+a_{L}\right)-\beta p\left(\bar{\lambda}+a_{H}\right)}-\frac{\left[V_{H}-p V_{L}\right]}{\gamma+\bar{\lambda}+a_{H}}
\end{aligned}
$$

From Equation (3), $a_{H}$ decreases with $\bar{\lambda}$ if and only if $V_{H}-p V_{L}$ increases with $\bar{\lambda}$. That is,

$$
\frac{d a_{H}}{d \bar{\lambda}} \leq 0 \quad \Leftrightarrow \quad \frac{d\left[V_{H}-p V_{L}\right]}{d \bar{\lambda}} \geq 0 \quad \Leftrightarrow \quad p \frac{d V_{L}}{d \bar{\lambda}} \leq \frac{d V_{H}}{d \bar{\lambda}} .
$$

Following substitution and extensive algebra, this is true whenever

$$
\left(\gamma+\beta(1-p)+\bar{\lambda}+a_{L}\right)\left[V_{H}-p V_{L}\right] \leq p \gamma V_{L}
$$

This inequality must fail when $p$ is small. To see this, note that Equation (11) implies that $\gamma\left[V_{H}-p V_{L}\right] \leq p \gamma V_{L}$, or upon re-arrangement $2 p \geq V_{H} / V_{L} \geq 1$. Hence, if $p<\frac{1}{2}$ then 
Equation (11) must fail. This implies that for such lower levels of protection, the activity of a clean minister increases with $\bar{\lambda}$. On the other hand, Equation (11) can hold for higher levels of $p$. To see this, note that for $p=1$ the inequality becomes $\left(\gamma+\bar{\lambda}+a_{L}\right)\left[V_{H}-V_{L}\right] \leq \gamma V_{L}$. Now, let $\beta$ grow large, so that a tainted minister recovers rapidly. An inspection of Equation (2) confirms that $\left(V_{H}-V_{L}\right) \rightarrow 0$ as $\beta \rightarrow \infty$. Thus, for $\beta$ large and $p=1$ (in fact, for $p$ large enough) the left-hand side of (11) is close to zero, and hence the activism of a clean minister falls with $\bar{\lambda}$.

Lemma 3. Under the quadratic-loss specification of Equation (5) and in a squeaky clean cabinet,

$$
a_{H}=\frac{1}{2}\left[\bar{a}-\gamma-\bar{\lambda}+\sqrt{(\bar{a}+\gamma+\bar{\lambda})^{2}-\frac{2 \bar{v}}{\theta}}\right]
$$

so long as $\bar{v} \leq 2 \bar{a} \theta(\gamma+\bar{\lambda})$. Otherwise, the minister chooses $a_{H}=0$.

Proof. Given $\lambda(a)=a$, Equation (5), and $p=0$, Equations (1) and (3) become

$$
\left(\gamma+\bar{\lambda}+a_{H}\right) V_{H}=\bar{v}-\frac{\theta\left(\bar{a}-a_{H}\right)^{2}}{2} \text { and } \theta\left(\bar{a}-a_{H}\right)=V_{H}
$$

These two equations combine to eliminate $V_{H}$, and following re-arrangement

$$
\frac{\left(\bar{a}-a_{H}\right)^{2}}{2}-(\gamma+\bar{\lambda}+\bar{a})\left(\bar{a}-a_{H}\right)+\frac{\bar{v}}{\theta}=0
$$

Finding the appropriate root of this quadratic yields a solution for $\left(\bar{a}-a_{H}\right)$ and hence Equation (12). Checking to ensure that $a_{H} \geq 0$ leads to $\bar{v} \leq 2 \bar{a} \theta(\gamma+\bar{\lambda})$.

Proof of Proposition 3. The claims follow from Lemma 3 and an inspection of Equation (12).

Before proving Propositions 4 and 5, we observe that Equations (6) and (7) solve to yield $\hat{\gamma} W_{H}=\alpha_{H} w\left(a_{H}\right)+\left(1-\alpha_{H}\right)\left(w\left(a_{L}\right)-\delta\right)$ and $\hat{\gamma} W_{L}=\alpha_{H} w\left(a_{H}\right)+\left(1-\alpha_{L}\right)\left(w\left(a_{L}\right)-\delta\right)$ where

$$
\alpha_{H}=\frac{\hat{\gamma}+\beta+\lambda\left(a_{L}\right)}{\hat{\gamma}+\beta+p \lambda\left(a_{H}\right)+\lambda\left(a_{L}\right)} \quad \text { and } \quad \alpha_{L}=\frac{\beta+\lambda\left(a_{L}\right)}{\hat{\gamma}+\beta+p \lambda\left(a_{H}\right)+\lambda\left(a_{L}\right)}
$$


Lemma 4. Evaluated at either $p=0, \beta=0$, or both, increased protection satisfies

$$
\frac{d W_{H}}{d p}>0 \Leftrightarrow \frac{d a_{H}}{d p} \times[\underbrace{w^{\prime}\left(a_{H}\right)}_{\text {(i) }}-\underbrace{p \lambda^{\prime}\left(a_{H}\right)\left(W_{H}-W_{L}\right)}_{\text {(iv) }}]>\underbrace{\lambda\left(a_{H}\right) \times\left(W_{H}-W_{L}\right)}_{\text {(iii) }},
$$

where the labels (i), (iv), and (iii) correspond to the effects described in the main text.

Proof. Differentiate Equation (6) with respect to $p$ to obtain

$\hat{\gamma} \frac{d W_{H}}{d p}=\frac{d a_{H}}{d p} \times\left[w^{\prime}\left(a_{H}\right)-p \lambda^{\prime}\left(a_{H}\right)\left(W_{H}-W_{L}\right)\right]-\lambda\left(a_{H}\right)\left(W_{H}-W_{L}\right)-p \lambda\left(a_{H}\right)\left[\frac{d W_{H}}{d p}-\frac{d W_{L}}{d p}\right]$.

If $p=0$ then the final term disappears, and the claim holds. If $p>0$, however, then the last term matters. To assess the last term, differentiate Equation (7) with respect to $p$ and set $\beta=0$ to obtain

$$
\begin{aligned}
\hat{\gamma} \frac{d W_{L}}{d p} & =\frac{d a_{L}}{d p} \times\left[w^{\prime}\left(a_{L}\right)+\lambda^{\prime}\left(a_{L}\right)\left(W_{H}-W_{L}\right)\right]+\left(\beta+\lambda\left(a_{L}\right)\right)\left[\frac{d W_{H}}{d p}-\frac{d W_{L}}{d p}\right] \\
& =\lambda\left(a_{L}\right)\left[\frac{d W_{H}}{d p}-\frac{d W_{L}}{d p}\right] \\
& \Rightarrow p \lambda\left(a_{H}\right)\left[\frac{d W_{H}}{d p}-\frac{d W_{L}}{d p}\right]=\frac{\hat{\gamma} p \lambda\left(a_{H}\right)}{\lambda\left(a_{L}\right)} \times \frac{d W_{L}}{d p}=\frac{\hat{\gamma} p \lambda\left(a_{H}\right)}{\hat{\gamma}+\lambda\left(a_{L}\right)} \times \frac{d W_{H}}{d p} .
\end{aligned}
$$

The second equality follows from the fact that $\beta=0$ and hence $a_{L}$ is unaffected by $p$. The final statement follows from straightforward algebra. Substituting into the first equality of the proof,

$$
\hat{\gamma}\left[1+\frac{p \lambda\left(a_{H}\right)}{\hat{\gamma}+\lambda\left(a_{L}\right)}\right] \frac{d W_{H}}{d p}=\frac{d a_{H}}{d p} \times\left[w^{\prime}\left(a_{H}\right)-p \lambda^{\prime}\left(a_{H}\right)\left(W_{H}-W_{L}\right)\right]-\lambda\left(a_{H}\right)\left(W_{H}-W_{L}\right) .
$$

An inspection of this yields the claim of the lemma for $\beta=0$.

In the main text (prior to Proposition 4) we claim that only three effects are present when recovery is impossible. This claim follows directly from Lemma 4.

Proof of Proposition 4. Straightforward algebra confirms that, when $\alpha_{H}$ and $\alpha_{L}$ are taken from Equation (13), $\hat{\gamma}\left(W_{H}-W_{L}\right)=\left(\alpha_{H}-\alpha_{L}\right) \times\left(w\left(a_{H}\right)-w\left(a_{L}\right)+\delta\right)$. When $p=0, \alpha_{H}=\alpha_{L}$ 
(from Proposition 1), and hence $\hat{\gamma}\left(W_{H}-W_{L}\right)=\left(\alpha_{H}-\alpha_{L}\right) \delta$. Now taking this and Equation (13), we can substitute into Equation (14), to obtain

$$
\frac{d W_{H}}{d p}>0 \Leftrightarrow \frac{d a_{H}}{d p} \times w^{\prime}\left(a_{H}\right)>\frac{\lambda\left(a_{H}\right)}{\hat{\gamma}+\beta+\lambda\left(a_{L}\right)} \times \delta .
$$

The claims of the proposition now follow by inspection.

Lemma 5. Under the conditions of Proposition 5, and evaluated at $p=0$,

$$
\frac{d W_{H}}{d p}>0 \Leftrightarrow \frac{\delta}{\psi} \leq R \quad \text { where } \quad R=\frac{\gamma\left(\bar{a}-a_{H}\right)^{2}}{\gamma+\bar{\lambda}+a_{H}}\left[1+\frac{\hat{\gamma}+\beta}{\bar{\lambda}+a_{H}}\right]
$$

Proof. Equation (1) becomes $\theta\left(\bar{a}-a_{H}\right)=\left[V_{H}-p V_{L}\right]$. Differentiating with respect to $p$,

$$
\frac{d a_{H}}{d p}=-\frac{1}{\theta} \frac{\partial\left[V_{H}-p V_{L}\right]}{\partial p}=\frac{\gamma}{\theta\left[\bar{\lambda}+a_{H}\right]} \frac{d V_{H}}{d p}
$$

where the second inequality follows from Equation (9) in the proof of Lemma 1. Evaluated at $p=0$, Equation (9) from that proof also reveals that

$$
\frac{d V_{H}}{d p}=\frac{\left[\bar{\lambda}+a_{H}\right] V_{L}}{\gamma+\bar{\lambda}+a_{H}} \Rightarrow \frac{d a_{H}}{d p}=\frac{\gamma V_{L}}{\theta\left[\gamma+\bar{\lambda}+a_{H}\right]}=\frac{\gamma V_{H}}{\theta\left[\gamma+\bar{\lambda}+a_{H}\right]}=\frac{\gamma\left(\bar{a}-a_{H}\right)}{\gamma+\bar{\lambda}+a_{H}}
$$

where the penultimate equality follows from the fact that $V_{L}=V_{H}$ when $p=0$ and the final equality from substitution of $\theta\left(\bar{a}-a_{H}\right)=V_{H}$. Setting $p=0$, taking the various expressions and substituting into Equation (14), we obtain the claim of the lemma.

Proof of Proposition 5. The term $R$ comes from Lemma 5. The claims regarding $\delta$ and $\psi$ follow by inspection. Similarly, by inspection, $R$ is decreasing in $\bar{\lambda}$ and $a_{H}$. Since $a_{H}$ is increasing in $\bar{\lambda}$, this means that the expression above is indeed decreasing in $\bar{\lambda}$. It is increasing in $\beta$; comparative statics with respect to $\theta$ and $\bar{v}$ follow from the corresponding properties of $a_{H}$.

Proofs of Propositions 6 and 7. These results from arguments given in the text. 


\section{NOTES}

${ }^{1}$ The idea that policy efforts are correlated with political risk has been developed by others. Dal Bó, Dal Bó and Di Tella (2004) modeled a politician who is either bribed or threatened by an interest group. Certain activities are costly because the group may harm the politician, and furthermore the politician will not receive the bribe. The authors observed that increased activism may lead to resignation calls, by noting that politicians may (p. 7) "... claim that their own actions are constrained by the influence of pressure groups that might resort to smear campaigns in the media and legal harassment." Dal Bó and Di Tella (2003) developed the same model but where the politician may be protected by a political party that prevents costly attacks by pressure groups. In our paper, a prime minister experiences political unpopularity in order to resist a resignation call.

${ }^{2}$ Our focus on career concerns, rather than conflicting policy objectives, differentiates our approach from other principal-agent studies. Thies (2001), for example, focused on delegation in multi-party governing coalitions in the presence of policy conflict between ministers.

${ }^{3}$ This feature distinguishes our model from the contractual solutions to moral-hazard problems that occur in economics. In the classic economic setting, a principal provides an incentive to an agent to supply effort by offering a performance bonus via a noisy proxy measure; for instance, the agent may be paid according to output, which depends on both effort and some exogenous noise. The principal can always ensure first-best effort by setting the bonus high enough. However, this exposes the risk-averse agent to an inefficient risk premium. The central trade-off is between risk and incentives. Here, however, the principal (that is, the prime minister) is actually unable to impose the first-best effort (that is, activism) since the tools available to her are too coarse.

${ }^{4}$ Much of our analysis extends to the case where the minister receives $v_{H}(a)$ when clean and $v_{L}(a) \leq v_{H}(a)$ when tainted, so that he dislikes the experience of a scandal. We assume that the minister's benefit function is a concave and continuously differentiable function of his activism. 
${ }^{5}$ Since $v(a)$ is concave and $\lambda(a)$ is convex, we can use the the first-order condition (1) to characterize a solution to the minister's optimization problem. It applies for an interior solution; $a_{H}=0$ may be a solution if $v^{\prime}(0) \leq \lambda^{\prime}(0)\left(V_{H}-p V_{L}\right)$. Similarly, the Equation (2) ties down the solution for a tainted minister, with the caveat that $a_{L}=0$ would follow if $v^{\prime}(0) \leq \lambda^{\prime}(0) V_{L}$.

${ }^{6}$ This claim leans upon the concavity of $v(a)$ and the convexity of $\lambda(a) ; a_{L}$ is inversely related to $V_{L}$. Similarly, for a clean minister, $a_{H}$ is inversely related to $V_{H}-p V_{L}$.

${ }^{7}$ Equivalently, the prime minister promises to protect all ministers who experience a first-strike scandal; there are no probabilities involved in her decision. In order to achieve varying degrees of protection, she varies the definition of what constitutes a first-strike scandal. Thus, a stricter definition of a scandal corresponds to increased protection.

${ }^{8}$ We have assumed that every minister reacts to the prime minister's failure to keep her promises in the same way. This helps to simplify the exposition, but does not constrain our results. If, following her deviation, we allowed the prime minister to lose her reputation with only a subset of her cabinet then Proposition 6 would continue to hold. The prime minister faces a problem when there is insufficient reputational slack in her relationship with a minister. When all ministers are identical, collecting together any subset of relationships cannot help, simply because there is no spare slack to share. This point (which does not depend upon the symmetric treatment of different ministers) means that heterogeneity of the cabinet (Propostion 7) is important.

${ }^{9} \mathrm{~A}$ direct analogy is with the literature on political parties. Krehbiel (1993) queried how the world would look if legislators simply acted according to their preferences; thus he challenged political scientists to find evidence of "partisan" behavior. Both Levy (2004) and Morelli (2004) suggested that parties might enable credible commitments. Our analysis has a similar flavor.

${ }^{10}$ Indridason and Kam (2005a), for example, showed that competition between ministers means that cabinet re-shuffles can be used to mitigate against overspending in a department. 


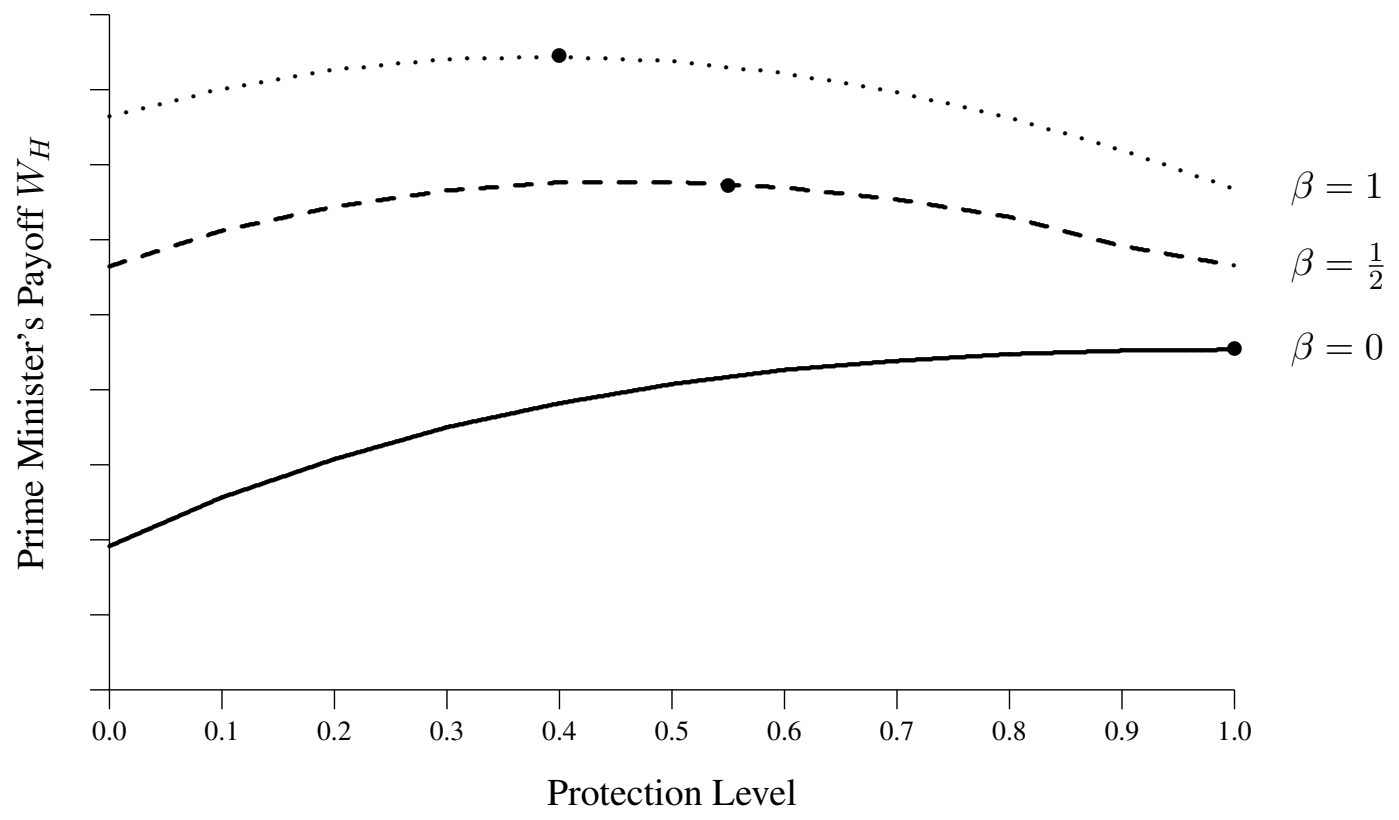

(a) The Effect of Recovery

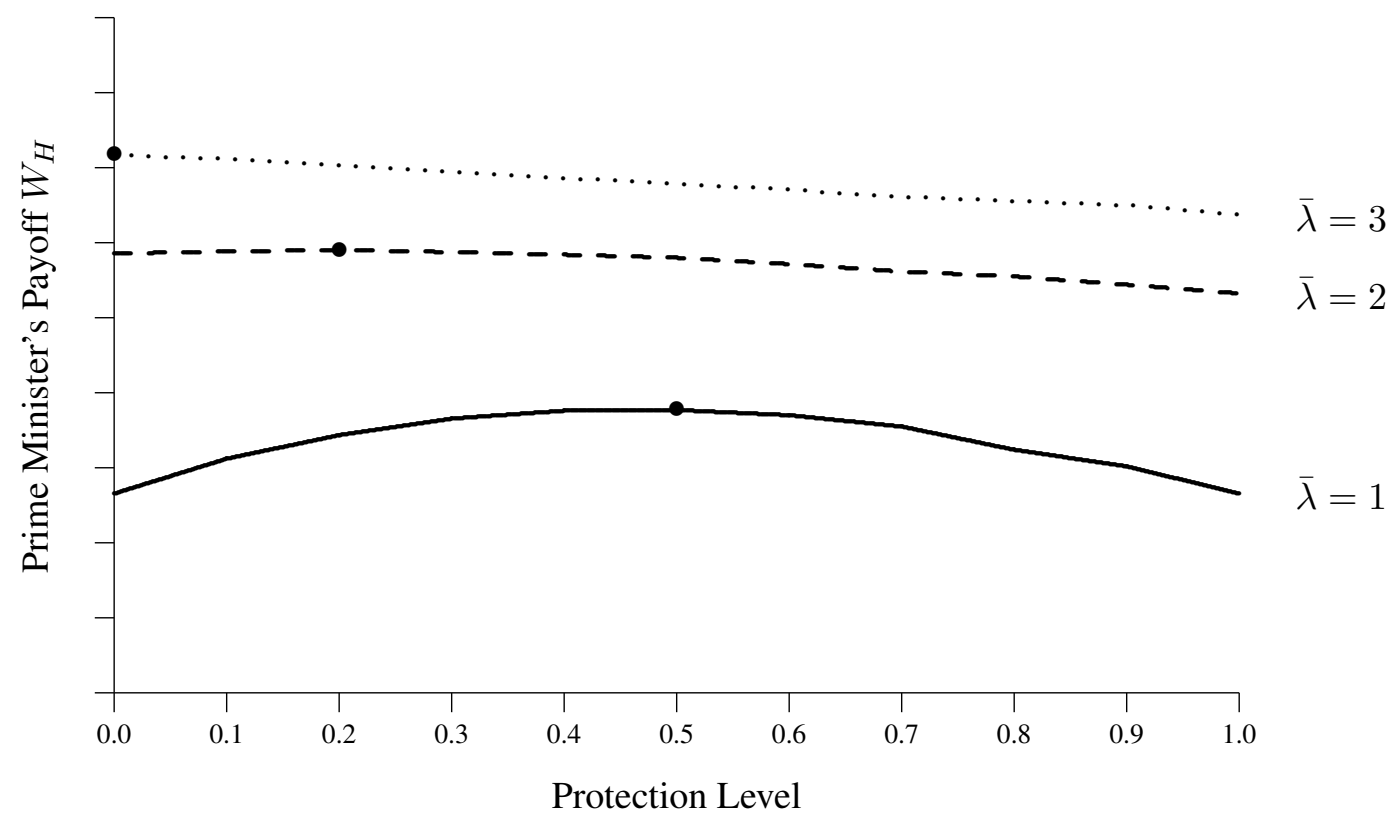

(b) The Effect of the Background Risk

For these illustratations, scandals arrive with hazard rate $\bar{\lambda}+a$. The minister's preferences satisfy the quadratic-loss specification of Equation (5), with $\bar{a}=1$, $\bar{v}=2$ and $\theta=1$. The prime minister's payoffs are of the form given in Equation (8) with $\delta=1 / 2$ and $\psi=6$. Both the prime minister and a cabinet member share the same discount rate $\gamma=\hat{\gamma}=8 / 10$. For Figure 1(a) we set $\bar{\lambda}=2$, and for Figure 1(b) we set $\beta=1 / 2$. A bullet “ $\bullet$ " indicates the approximately optimal choice of $p$. 


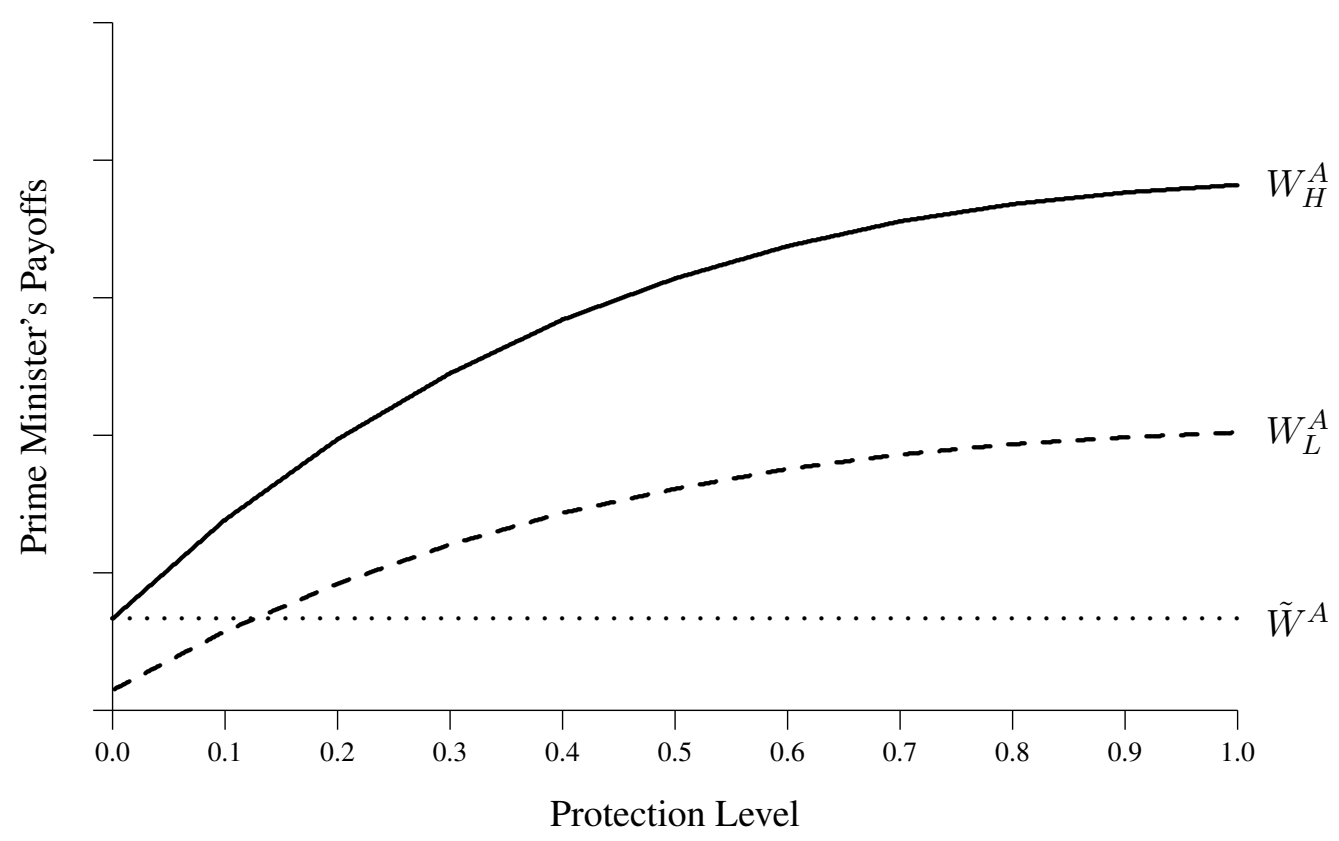

(a) Minister $A$, with Recovery Rate $\beta=0$ )

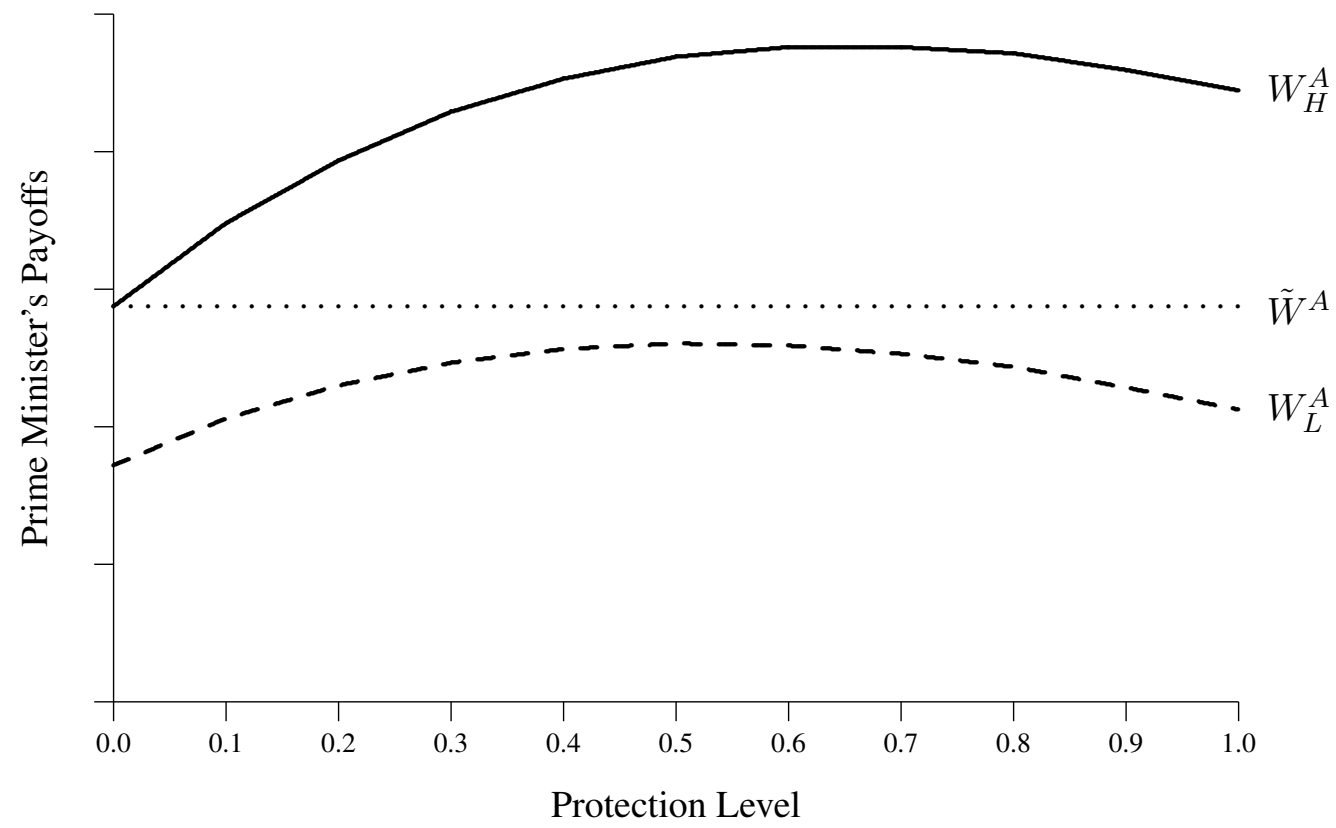

(b) Minister $B$, with Recovery Rate $\beta=\frac{1}{4}$

Once again, scandals arrive with hazard rate $\bar{\lambda}+a$ where $\bar{\lambda}=1$ and ministers' preferences satisfy Equation (5), with $\bar{a}=1, \bar{v}=2$ and $\theta=1$. The prime minister's payoffs of the form of Equation (8) satisfying $\delta=1 / 4$ and $\psi=6$. Both the prime minister and a cabinet member share the same discount rate $\gamma=\hat{\gamma}=8 / 10$.

FIgURE 2. Achieving Credibility with a Multi-Member Cabinet 